\title{
MIGRAÇÃO E URBANIZAÇÃO NO BRASIL alguns desafios metodológicos para análise
}

\author{
José Marcos Pinto da Cunha
}

\begin{abstract}
Resumo: A partir de um olhar demográfico, este artigo tem por objetivo apresentar algumas reflexões sobre questões relevantes para a análise de migração e urbanização, considerando os avanços e lacunas existentes e, principalmente, as possibilidades analíticas propiciadas pelo uso criativo dos Censos Demográficos brasileiros mais recentes. Pretende-se contribuir não apenas para a ampliação da agenda de estudos, mas também para uma reflexão teórico-metodológica sobre os fenômenos em questão. Palavras-chave:Urbanização. Migração interna. Censo demográfico.
\end{abstract}

\begin{abstract}
Based on a demographic perspective, this article presents a discussion on important issues for analyses of migration and urbanization, considering the existent advances and gaps and, especially, the analytic possibilities propitiated by creative use of the most recent Brazilian Demographic Censuses. The article is intended as a contribution not only to a broadening of the agenda for research, but also to theoretical and methodological discussions on the phenomena in question.

Key words: Urbanization. Internal migration. Demographic census.
\end{abstract}

$\mathrm{N}$ as últimas décadas, a questão migratória no Brasil deixou de concentrar-se apenas no clássico movimento rural-urbano que, nos anos 50 e 60 , preocupou e mobilizou a maior parte dos estudos. As migrações inter-regional, intra-regional, internacional e a mobilidade pendular (commuting) e a sazonal são cada vez mais reconhecidas como faces distintas desse fenômeno demográfico que aflora e ganha importância qualitativa e quantitativa em função das modificações ocorridas nas dimensões econômica, social e política em nível nacional e internacional.

Da mesma forma, a questão da urbanização - que vinha sendo concebida como algo irreversível e inexorável, devido à evolução dos indicadores até então moldados para este fim - também passa a ser, se não contestada, ao menos questionada quanto ao seu real significado, uma vez que novas formas de assentamentos humanos passam a surgir, como fruto de mudanças nas relações econômicas e sociais entre o campo e a cidade. $O$ mais interessante a notar é que tais preocupações, que surgem no Brasil em alguns estudos, também encontram seus correspondentes no plano internacional (CHAMPION, 2003).

É inegável que o conhecimento adequado dos tipos e etapas da migração, suas características, significados e condicionantes são requisitos fundamentais para entender não apenas a dinâmica demográfica atual, mas também para prever suas tendências futuras. Há, no entanto, quem questione se a rede urbana brasileira e suas áreas rurais realmente estariam passando por uma percepção mais adequada do que seriam suas verdadeiras características, definindo as necessidades e vocações do urbano e, sobretudo, do rural brasileiro - e, como consequiência, suas 
implicações sobre políticas sociais, demográficas e econômicas. Há que se considerar a grande dificuldade de geração de dados para a mensuração da migração, devido à sua peculiaridade com relação às demais variáveis demográficas. Tratando-se de um fenômeno com múltiplas expressões espaciais e temporais, a migração não possui uma única definição - fato que constrange qualquer tentativa de sistematização e levantamento de dados e estimativas. Do lado da urbanização, também se percebe que os dados existentes que, via de regra, rendem-se às definições oficiais, da mesma forma podem deixar a desejar quando o que se deseja é mensurar a sua real dimensão. Além disso, os critérios usados para classificar alguma localidade como "urbana" ou "rural", longe de serem consensuais, parecem também carecer de reflexão crítica - e alguns deles serão discutidos neste texto.

$\mathrm{O}$ atual estado de conhecimento e os avanços nos estudos migratórios e sobre a urbanização brasileira revelam a riqueza de estudos até então desenvolvidos. Da mesma forma, refletem os esforços sistemáticos no sentido da geração e contínua evolução dos dados específicos e técnicas de análise, bem como novos enfoques sobre como conceber e analisar ambos os fenômenos.

Assim sendo, nos dias de hoje, tem-se uma boa visão da questão migratória e do processo de urbanização brasileiro no sentido de que se tem consciência das principais tendências e processos ocorridos e ainda vigentes no país. Contudo, muitos aspectos ainda carecem de estudos - o que abre uma agenda bastante extensa para os estudiosos dessas áreas.

Assim, no presente momento, se por um lado nos deparamos com várias modalidades de deslocamentos populacionais que carecem não somente de uma reflexão interpretativa, mas também de uma tarefa sistemática de mensuração e caracterização, por outro, desenvolveu-se toda uma discussão sobre o significado, dimensão e importância do rural brasileiro e de suas relações com o urbano.

No caso da migração, pode-se dizer que muitos desses fenômenos dificilmente poderiam ser estudados a partir das informações recolhidas nos Censos ou na Pesquisa Nacional por Amostras Domiciliares - PNAD. Tal é o caso, por exemplo, das migrações sazonais, uma vez que os levantamentos têm o cuidado de acontecerem justamente em momentos em que esse tipo de movimentação é menos significativo. O mesmo ocorre com certas facetas dos movimentos migratórios que aparentemente não poderiam ser estudadas com as informações tradicionalmen- te disponíveis - como seriam os casos das "redes", as trajetórias migratórias, as estratégias familiares para migração, etc.

Embora tenha havido avanços quanto à urbanização, ao que parece, os estudos ainda estão distantes de apresentar claros consensos e um conjunto de informações que possam dar conta da complexidade que enfrenta o estudioso sobre dinâmicas sociais, econômicas e demográficas do ponto de vista da "situação do domicílio" da população.

Ao contrário dos anos 80 , a presente década presenciou um aumento significativo dos estudos migratórios e da abordagem de questões emergentes. Pode-se dizer que nos últimos cinco anos as análises sobre migração apresentaram uma grande dinamização, pondo fim no quase estado de letargia a que esteve fadada no decênio 1980/ 90, quando nem a grande riqueza dos dados censitários sobre o tema foi suficientemente capaz de motivar os estudiosos. Guardadas as devidas proporções, já que o caso da migração parece ter sido mais grave, também o fenômeno da urbanização pôde beneficiar-se de importantes estudos realizados no final da década de $90 .{ }^{1}$

Hoje, devido à série invejável de fontes de dados, o interessado em migração tem à sua disposição enormes possibilidades de contribuir para completar as várias lacunas dessa área temática. Contudo, deve estar preparado para enfrentar as limitações analíticas, via de regra impostas pelas coletas censitárias, as quais, possivelmente, podem desmotivar o uso desses ricos bancos de dados. Por outro lado, a urbanização também não deixa de impor desafios significativos aos que dela se ocupam, por ser muito mais complexa no Brasil atual, apesar de todas as discussões teóricas e conceituais desenvolvidas até aqui e as reflexões delas decorrentes, inclusive no que tange à forma de coleta de dados.

O presente artigo visa a resgatar algumas questões instigantes que surgem dos debates em torno da migração e da urbanização. Sem a pretensão de ser conclusivo ou exaustivo, este trabalho, com um claro viés demográfico, tem por objetivo refletir sobre algumas problemáticas de interesse, a forma como elas têm sido abordadas e, principalmente, suas possibilidades de análise a partir das informações provenientes particularmente dos Censos Demográficos brasileiros mais recentes. Portanto, este texto tem a clara opção de privilegiar os dados censitários, por considerar que estes são os dados mais completos e representativos, em termos espaciais, de ambos os fenômenos. 


\section{ANÁLISE DE MIGRAÇÃO A PARTIR DOS DADOS CENSITÁRIOS}

\section{Identificação dos Fluxos Migratórios}

Trabalho recente apontou as principais características e mudanças da migração nas últimas décadas no Brasil (CUNHA; BAENINGER, 2005). Tais transformações dizem respeito não apenas às tendências históricas, mas também à emergência e/ou intensificação de certos processos que, mesmo presentes, até a década de 70 eram encobertos pela grande importância dos movimentos migratórios interestaduais e, em particular, aqueles do tipo rural/urbano.

Tal é o caso da migração de retorno, que se intensificou significativamente a partir dos anos 80; dos movimentos intra-regionais que afloraram nesse período, revelando novas lógicas e "espaços de migração" (BAENINGER, 1999); os fluxos migratórios intra-estaduais, que refletem as relações existentes entre as áreas metropolitanas (ou grandes aglomerações urbanas) e o interior; finalmente, os intrametropolitanos, que se reproduzem com formas semelhantes em praticamente todas as áreas metropolitanas do país, muito embora não necessariamente com os mesmos condicionantes. A essas modalidades não se poderia deixar de agregar os movimentos migratórios internacionais que, a partir dos anos 90, assumiram uma importância numérica que obrigou os demógrafos a reconsiderar a hipótese de "Brasil como uma população fechada". 2 A mensuração e interpretação de todas essas formas de migração, sejam elas as mais tradicionais, recrudescentes ou emergentes, representam uma condição necessária - embora não suficiente - para se avançar na compreensão de parte considerável da dinâmica demográfica e da heterogeneidade socioespacial existente no país. De fato, devese considerar que “... além das grandes tendências em termos dos fluxos migratórios interestaduais, não se pode negligenciar a importância das dinâmicas intra-regionais e especialmente intra-estaduais para se compreender o processo de redistribuição da população no Brasil" (CUNHA; BAENINGER, 2005).

É indiscutível que um dos grandes obstáculos a ser transposto pelo estudioso de migração são as fontes de dados. No Brasil, a não ser que se possa contar com uma pesquisa específica - o que, em geral, não ocorre devido ao seu alto custo - o pesquisador dispõe basicamente dos Censos Demográficos e, para os anos 90, das PNADs. ${ }^{3}$ Nesse último caso, as informações são praticamente as mesmas disponíveis nos Censos, motivo pelo qual, a partir daqui, o texto restringe-se a eles. ${ }^{4}$

Na verdade, os Censos Demográficos brasileiros, principalmente os três últimos (1980, 1991 e 2000), apresentam grandes potencialidades em termos de análise do fenômeno migratório. Além da representatividade e alcance espacial, característicos desses levantamentos, os três censos dispõem de um grande número de itens especificamente voltados a apreender diferentes facetas do fenômeno. Entre eles, destacam-se os que permitem estabelecer fluxos migratórios a partir da identificação do município de residência anterior do indivíduo ou de sua residência em um momento no passado. ${ }^{5}$

É importante frisar, contudo, que as oportunidades oferecidas pelos Censos Demográficos crescem ainda mais se consideramos as possibilidades dos inúmeros cruzamentos dos quesitos sobre migração entre si, e desses com as demais informações levantadas a respeito das características demográficas e socioeconômicas da população.

Como mostram os trabalhos de Carvalho (1985), Martine (1984), Carvalho e Machado (1992), Carvalho e Rigotti, (1998) e Rigotti (1999), a correta utilização dos dados censitários sobre migração permite enfrentar uma série de questões relativas ao fenômeno. Tendo em vista a clareza e amplitude dos trabalhos acima mencionados, considerase desnecessário reproduzir aqui, em detalhes, as várias possibilidades oferecidas pelos Censos Demográficos. Sendo assim, o que se apresenta à continuação é apenas uma visão geral da questão.

Grosso modo, pode-se dizer que, a partir desses dados, seria possível identificar três modalidades de migração:

- a interestadual;

- a intermunicipal;

- a migração entre situações de domicílio (rural-urbano, urbano-urbano, etc.).

Nos dois primeiros casos, os quesitos sobre "lugar de nascimento", "residência anterior" (conhecida como "última etapa") e "residência 5 anos antes do Censo" (conhecida como "data fixa"), seriam as possibilidades oferecidas, muito embora conceitualmente as três informações sejam significativamente distintas: no primeiro caso, capta apenas os migrantes acumulados (lifetime migrants) sem, portanto, estabelecer um período de migração; no segundo, apenas o último movimento do indivíduo dentro do período intercensitário; quanto à última informação, esta tem a vantagem de combinar espaço (município e UF) e tempo (cinco anos atrás), determinando a residência em uma 
data fixa no passado - o que especifica, ao contrário do quesito sobre "última etapa", um período exato e local inequívoco para a migração.

Nos Censos de 1980 e 2000, também se levantou o que se convencionou chamar de "movimento pendular" - a partir da pergunta sobre "lugar de trabalho" e "estudo". Contudo, dado suas características - movimento diário sem caráter permanente - tal fenômeno não deveria ser catalogado como migração, mas sim, genericamente, como um tipo de mobilidade populacional.

Mesmo atreladas a esses recortes espaciais, variações das modalidades de migrantes poderiam ser obtidas a partir da combinação entre as perguntas anteriores entre si e com outras, como aquela que se refere ao "tempo de residência" - o que ampliaria ainda mais as possibilidades de informação censitária. Nesse sentido, há que se destacar que a definição mais detalhada da trajetória dos indivíduos permitiria a construção de tipologias mais complexas dos movimentos - o que, sem dúvida, contribuiria para o enriquecimento da compreensão dos processos migratórios, seus condicionantes e conseqüências.

Como se adiantou, várias sugestões sobre cruzamentos possíveis a partir dos quesitos censitários sobre migração foram propostas por outros autores, em particular para o Censo de 1991, no qual, pela primeira e única vez, o Instituto Brasileiro de Geografia e Estatística - IBGE manteve duas informações sobre migração em nível municipal - "a última etapa" e "data fixa" - o que hoje se percebe ter sido um momento de transição para a consolidação nos censos da pergunta sobre "data fixa", utilizada há muito tempo nos censos de outros países.

O que é importante na contribuição desses autores, além, é claro, da forma didática como apresentam as possibilidades dos dados censitários, são as alternativas que o cruzamento de quesitos censitários pode dar ao pesquisador no sentido de criar novas modalidades de migração. Esse é o caso específico da identificação de outros pontos nas trajetórias municipais, a partir do uso conjunto do dado sobre "data fixa" e "última etapa", ou a identificação dos migrantes de retorno com o uso combinado de "local de residência" e "local de nascimento".

Infelizmente, essas possibilidades, pelo menos em nível municipal, não podem ser aproveitadas no caso do Censo Demográfico 2000, que levantou apenas a informação sobre "data fixa". De qualquer forma, ao menos para as Unidades da Federação - UFs, ambas as perguntas foram reproduzidas, - o que permitiria a aplicação dos esquemas sugeridos, muito embora estes fossem muito mais interessantes para os processos migratórios intra-estaduais e intra-regionais.

Considera-se que a inclusão da UF de nascimento nas possibilidades de combinações dos quesitos censitários pode implicar em significativos aportes analíticos, sobretudo se considerarmos que, em alguns estudos concretos, a simples identificação de um ou dois pontos na história migratória individual pode escamotear parte importante do processo. ${ }^{6}$

Esse tipo de ganho é típico, por exemplo, de estudos de processos de metropolitanização ou, mais especificamente, dos de crescimento e expansão urbana nas grandes cidades. Neste último caso, muitas vezes o peso da mobilidade intraregional pode mascarar o real processo migratório responsável pelo fenômeno que, via de regra, iniciou-se em outras regiões ou estados (MATOS, 1994; CUNHA, 1994). O mesmo ocorre com a migração para áreas de fronteiras, como mostram Cunha (2004) e Salim (1992). Segundo esse último autor, para o Centro-Oeste, pode-se observar "uma migração concentrada regionalmente, mas caracterizada pela razoável mobilidade interestadual, antes de situar-se na Região". Nesse caso, é bastante clara a necessidade de se conhecer mais detalhadamente a trajetória dos migrantes para que se possa chegar a uma adequada interpretação das causas dessa migração.

Um detalhe metodológico importante, no que se refere à migração interestadual, é que a informação sobre "residência anterior" que consta nos Censos de 1980 e 1991 é, de certa forma, de natureza distinta daquela contida no Censo de 2000. Isso porque, nos dois primeiros casos, a "UF anterior" declarada pelos migrantes está atrelada ao município anterior declarado - e não seria, portanto, necessariamente a residência prévia real, em termos dessa unidade espacial. Em 2000, esse problema foi sanado, na medida em que a pergunta foi feita diretamente sobre a "UF" e não sobre o "município de residência anterior".

É sempre bom lembrar que uma solução para o problema dos Censos de 1991 e 1980, no que diz respeito a uma melhor estimativa de migração interestadual intercensitária, tem sido um ajuste com base na distribuição proporcional dos indivíduos que migraram dentro dos estados onde foram recenseados, mas residiam na UF há menos de 10 anos. Pelos critérios censitários, esses indivíduos, embora inequivocamente migrantes interestaduias, não são computados como tal, uma vez que sua residência anterior está atrelada ao município que, no caso, encontra-se dentro do Estado de recenseamento. Dessa forma, o procedimento adotado é assumir que a distribuição desses migrantes segundo UF 
de residência anterior é a mesma observada para aqueles que migraram diretamente de suas UF de origem. ${ }^{7}$

Nos Censos de 1991 e 2001, a informação específica sobre "município de residência em uma data fixa no passado" (no caso, 1986 e 1995, respectivamente) não apenas permite a reconstituição da população no meio do período intercensitário - e, portanto, que possam ser obtidas estimativas de saldos migratórios para dois intervalos distintos de tempo (CARVALHO; MACHADO, 1992) - como também elimina um problema de referência espacial intrínseco à informação sobre o "município de residência anterior".

De fato, como o município anterior pode não ser o mesmo, por exemplo, que a microrregião anterior ou Estado anterior, não é possível estudar, de maneira adequada, fluxos em um nível espacial mais agregado que os municípios. Contudo, a informação sobre a residência em uma "data fixa" determina sem ambigüidade o local onde o indivíduo residia, seja qual for o recorte espacial utilizado (há cinco anos a pessoa vivia no mesmo bairro que pertence a um único município, que pertence a uma única região, etc.).

Deve-se lembrar ainda, conforme Rigotti (1999), que, ao fixar exatamente um período de migração, essa informação é a mais adequada para a construção de taxas de migração - tão úteis não apenas para mensurar a intensidade do fenômeno, mas também nos procedimentos de projeção demográfica.

No entanto, esse tipo de informação possui também algumas limitações, sendo que duas delas mereceriam destaque: - não permite identificar a migração de menores de 5 anos. Essa lacuna tem que ser preenchida por métodos indiretos - como é o caso das relações que envolvem a migração líquida de mulheres em idade fértil e a relação crianças/ mulheres, ${ }^{8}$ ou por meio de estimativas, também indiretas, da fecundidade das mulheres migrantes;

- não contempla os movimentos ocorridos dentro do período transcorrido entre o levantamento e a data fixada no passado. Esse é um dos motivos pelos quais essa informação é qualitativa - e quantitativamente - distinta daquela derivada do item "residência anterior" para pessoas com menos de cinco anos de residência;

- em particular, essa última limitação tem importantes implicações nos estudos sobre a dinâmica intrametropolitana, uma vez que os movimentos migratórios internos são visivelmente subestimados a partir dessa informação. ${ }^{9}$

Por último, seria importante fazer algumas ponderações sobre as dificuldades de comparação entre os Censos
Demográficos, em particular entre os três últimos (1980, 1991 e 2000), em função da retirada do quesito referente à "ultima etapa" do indivíduo em nível municipal, no Censo de 2000. Não seria possível, por exemplo, uma análise temporal que envolvesse o Censo de 1980. Afinal, ao contrário do de 1991, aquele somente conta com a informação sobre "última etapa" migratória, em nível municipal - e o de 2000 somente apresenta o item "data fixa".

Assim, uma forma de aproximação que vem sendo aceita pelos estudiosos do assunto ${ }^{10}$ seria o uso da "última etapa" combinada com o tempo de residência menor de 5 anos. Ou seja, tenta-se com isso delimitar também para o Censo de 1980 um período temporal semelhante ao item "data fixa" coletado em 1991 e 2000 - muito embora se saiba que, por não se tratar de um período exato de tempo, tal comparação fique teoricamente comprometida. Na verdade, ainda que delimitado por um corte temporal, não é possível saber a que período se refere o conjunto de migrantes de "última etapa", uma vez que estes são enumerados segundo distintos momentos de chegada (dado pelo tempo de residência). ${ }^{11}$

\section{Análises sobre as Características da Migração}

Como se observou, a periodicidade pode comprometer o acompanhamento desse fenômeno tão dinâmico que é a migração. Além dela, várias outras limitações cercam os dados censitários - e talvez uma das mais importantes seja seu caráter não-retrospectivo.

Assim, tirando algumas poucas exceções, como é o caso, por exemplo, do "município de residência anterior", não se coleta informação sobre a vida passada do informante sendo essa fonte praticamente uma "fotografia" da data referencial censitária. Em termos de estudos migratórios, tal característica representa uma grande limitação, pois impossibilita, por exemplo, qualificar os migrantes no momento de suas mudanças. Nesse particular, algumas alternativas podem ser levantadas no sentido de resolver ou, no mínimo, de paliar tais problemas.

Do ponto de vista de algumas das variáveis demográficas com claros significados analíticos para o estudo da migração, a idade, tipo de família, ciclo vital e estado civil seriam passíveis de modificação com o tempo e/ou com a migração. Portanto, poderiam não refletir a situação no local de origem. A seguir, apresentam-se algumas sugestões de manuseio desses dados:

- (i) Idade: um procedimento bastante aceitável para transformá-la em "idade ao momento da migração" seria 
subtrair seu valor do "tempo de residência no município" do indivíduo; ${ }^{12}$

- (ii) Tipo de Família: tendo como referencial o chefe da família, pode-se cotejar a "condição migratória" (origem do movimento e tempo de residência no destino) deste e dos outros membros como forma de se obter pistas aproximadas sobre a situação dessa família no momento da migração (se já existia, se era tal como captada pelo Censo, etc.). Essa tentativa foi feita com relativo sucesso por Cunha, (1994), para analisar o processo de fragmentação e recomposição das famílias de migrantes intrametropolitanos com origem em outros Estados, e por Ribeiro (1997), para estimar os efeitos diretos e indiretos da migração de retorno.

- (iii) Ciclo Vital: tomando como um indicador aproximado dessa variável a idade média do casal, ${ }^{13}$ o mesmo procedimento descrito em i poderia ser utilizado nesse caso;

- (iv) Estado Civil: assim como em ii, o estado civil do chefe da família poderia ser inferido a partir da comparação entre a sua condição migratória e a de seu cônjuge. ${ }^{14}$

Comentários semelhantes poderiam ser feitos para algumas características socioeconômicas:

- (i) Educação: como lembra Martine (1980), para a população mais adulta, esta variável estaria muito menos afetada pelo tempo e pela mudança de residência - o que a torna uma escolha interessante para os estudos migratórios que visem conhecer o perfil do migrante na origem do movimento;

- (ii) Ocupação: como se sabe, essa variável pode ser afetada pela simples mudança de quadro domiciliar (rural para urbano ou vice-versa) ou de contextos socioeconômicos. Contudo, uma vez que a análise seja feita com cautela, de forma a tomar em conta as áreas de origem dos migrantes (por exemplo, se é urbano ou rural, se vem de uma área industrial ou agrícola, se é originário de uma cidade pequena, média ou grande, etc. ), podem ser obtidas algumas indicações sobre a situação ocupacional anterior do indivíduo.

No Censo, também são captadas as informações apenas das pessoas "sobreviventes" (à mortalidade ou reemigração), o que equivale dizer que, para um determinado local, os dados com o quais se trabalha refletem apenas a situação daqueles que aí residiam no momento censitário, independentemente se lá estavam uma semana, ou mesmo um dia antes da data de referência.

Por esse motivo, as análises sobre seletividade, ${ }^{15}$ que comparam, por exemplo, migrante versus não-migrante com relação a tais variáveis, devem ser tomadas com cautela e critério - sobretudo, porque, para os migrantes mais antigos, as características levantadas na data do Censo podem diferir daquelas vigentes na época do movimento. Nesse caso particular, parece não haver uma solução aceitável; contudo, o problema poderia ser menor com relação à análise de variáveis que pouco alterem com o tempo. ${ }^{16}$

\section{A Questão da Migração de Retorno: sua Interpretação e Mensuração}

Um dos fenômenos migratórios que mais chamaram a atenção nas análises dos dados dos Censos Demográfico de 1991 e 2000 foi o crescimento sem precedente do volume da migração de retorno, em particular para os Estados considerados tradicionalmente como "de emigração" (CUNHA; BAENINGER, 2005).

[...] o volume de migração de retorno incrementou-se enormemente no país nos últimos 30 anos; na década de 90 houve incremento relativo da ordem de $221 \%$ em relação aos volumes dessa migração comparado com a década de 70. Este elevadíssimo incremento contribuiu para que o número de pessoas retornadas a seus estados de nascimento passasse de 1,1 milhão, nos anos 70, para quase 3,8 milhões, nos 90; estes volumes indicam a importância que, nos anos mais recentes, este tipo de mobilidade - sempre presente, porém em menor intensidade - passou a adquirir no cenário das migrações nacionais (CUNHA; BAENINGER, 2005).

Dessa forma, esse fenômeno surge como um tema importante para se entender o processo migratório da década de 80 , momento em que, como se sabe, o país atravessou uma grande crise econômica, sobretudo no primeiro qüinquiênio.

Pode-se pensar que o retorno estaria condicionado a um fator de "sucesso" na região de destino, e que, portanto, não necessariamente todos os que deixaram suas áreas de origem estariam propensos a voltar para lá. Na verdade, nos anos 80, a probabilidade de "sucesso" parece ter-se reduzido ainda mais, na medida em que as transformações produtivas ocorridas no Brasil e, em especial nos Estados receptores, como São Paulo, tornaram a incorporação do migrante no mercado de trabalho muito mais frágil que nas décadas anteriores. ${ }^{17}$

Na verdade, a análise desse tipo de migração vai além dos números e suscita algumas questões substantivas sobre a interpretação dos dados: afinal, qual seria o significado de retornar ao Estado de nascimento?

Como mostra Ribeiro (1997), com esses dados é possível definir vários tipos de retorno: para uma determina- 
da Região Geográfica, para o Estado e, finalmente, para o município de nascimento. Restaria, contudo, saber quais dessas modalidades, a princípio, puramente estatísticas, fariam sentido analítico e, mesmo assim, em que condições.

Na verdade, haveria que se discutir conceitualmente o que seria e qual o significado da "migração de retorno", tarefa ainda pouco enfrentada pelos demógrafos e estudiosos de população. ${ }^{18}$

Pode-se dizer, por exemplo, que o retorno estaria caracterizado apenas nos casos em que a migração se justificasse pelo "desejo" do indivíduo, ou das famílias, de recuperarem as raízes, a cultura ou, em termos mais genéricos, o "modo de vida" da área de origem?

Nesse sentido, parecem ser bastante promissoras as idéias de Domenach e Piconet (1990), que discutem a noção de espaço de vida ou residência-base e residência exterior, ${ }^{19}$ ao contrário da mudança pura e simples de residência. Esse conceito, segundo os autores, permitiria definir diversos tipos de fluxos, superando a dicotomia utilizada até agora entre mudanças definitivas e deslocamentos temporais, numa tentativa de explicar também as tendências de reversibilidade desses deslocamentos.

$\mathrm{Na}$ verdade, a existência de uma residência-base parece ocorrer no caso do fluxo migratório de retorno, sobretudo aqueles envolvendo o Nordeste e Sudeste, pois os migrantes mudam-se para os grandes centros urbanos do país, mas, idealmente, desejam voltar e, culturalmente, procuram não se desligar de sua região de origem, tentando recriar alguns desses eventos culturais originais. ${ }^{20}$

A partir da tipologia proposta por Domenach e Piconet (1990), ${ }^{21}$ pode-se, portanto, enquadrar os fluxos migratórios de retorno apenas como um momento final do processo tipificado pelos autores como "uma residência-base e uma ou mais residências exteriores sucessivas antes do retorno". Nesse caso, a primeira geração dos migrantes teria alta probabilidade de retorno, sendo que a geração nascida no lugar de destino teria menos chances de retornar, já que seriam socializados nos grandes centros urbanos.

Assim, esses autores trabalham com a idéia do caráter de reversibilidade dos movimentos que é dado pela préorientação do objetivo do retorno, em certo tempo. Assim, além dos elementos puramente econômicos, a manutenção de uma solidariedade familiar e social, o investimento em terras ou bens imóveis na região de origem, e o apoio financeiro acidental aos que ficaram são medidas culturais que organizam e fazem possível o retorno do migrante.
Em geral, ainda segundo os autores, a duração da "expatriação" marcaria um ciclo familiar completo. Durante esse ciclo, as relações com as famílias ou com a região de origem seriam mais ou menos freqüentes. $\mathrm{O}$ isolamento seria dado pelo custo e as dificuldades de transporte. As visitas tenderiam a ser mais curtas e mais frequientes - o que significa a debilitação da transmissão de valores culturais. A situação de retorno diria respeito, sobretudo, ao migrante - e muito menos a seus descendentes. Além disso, a maneira como os filhos se adaptariam na sociedade de destino influenciaria a eventual decisão de retorno dos pais.

Como se nota, ao se conceituar o retorno da maneira anteriormente apresentada, fica claro que os dados censitários não apenas seriam insuficientes para delimitar o fenômeno, mas poderiam ser utilizados apenas como uma referência, na medida em que nada garante que o que se está medindo reflita o retorno real ou apenas uma parte do processo de "residências sucessivas no exterior". ${ }^{22}$ Certamente que, para uma resposta mais precisa, seriam necessárias informações que somente poderiam ser captadas por entrevistas em profundidade com os atores.

Portanto, é fundamental que exista uma preocupação em dar sentido aos dados sobre migração de retorno, como forma de diferenciá-los dos demais deslocamentos populacionais. Apenas para exemplificar, considere-se o caso de retornados mineiros provenientes de São Paulo. Nesse caso, seria importante compreender e mostrar em que sentido o retorno daqueles nascidos no sul ou nordeste de Minas Gerais e que, no retorno, migraram para o Triângulo Mineiro (ao Oeste) seriam distintos dos paulistas (ou outra naturalidade) que fizeram o mesmo movimento. Faria algum sentido diferenciá-los?

Assim, algumas questões metodológicas poderiam ser mencionadas no sentido de, a partir dos dados censitários, darem contornos mais claros para o fenômeno da migração de retorno. Em primeiro lugar, quanto à própria mensuração. Como mostra Ribeiro (1997), o volume estimado a partir da informação censitária direta não corresponde à real dimensão do fenômeno, na medida em que não considera seus efeitos indiretos, particularmente, aqueles relacionados aos familiares (não naturais) que o retornado "acumulou" durante o tempo que esteve fora de sua área natal.

Uma segunda questão refere-se a certas desagregações possíveis para o fenômeno. Assim, a não ser no caso do retorno para o próprio município, que daria muito menos margem para uma discussão sobre o seu significado, outras formas de mensuração desse tipo de movimento, por 
exemplo, em nível estadual, poderiam ser mais bem qualificadas se algumas discriminações fossem feitas.

A possibilidade de cruzamentos das informações permite especificar melhor os movimentos. Assim, pode-se observar, por exemplo, se a migração deu-se para a Região Metropolitana - RM ou principal aglomeração urbana do respectivo Estado, para uma área vizinha ao Estado de última residência, etc. - sendo que esses novos elementos permitiriam melhor balizar a reflexão sobre o caráter do "retorno" captado. Também a utilização do tempo de residência seria um bom indicador para reconhecer aqueles cujo retorno aparentemente já tivesse um caráter mais definitivo.

\section{Sobre o Papel das Redes}

Questão cada vez mais recorrente nas discussões e estudos sobre migração internacional (MASSEY, 1987; TILLY, 1990; BOYD, 1989) entre outros, o papel das redes familiares - ou, de maneira mais genérica, das redes sociais no direcionamento, incremento e manutenção dos fluxos migratórios - tem sido reconhecido como elemento importante para o entendimento do processo migratório.

$[\ldots]$ the vast majority of potential long-distance migrants... draw their chief information for migration decisions... from members of their interpersonal networks, and rely on those networks for assistance both in moving and in settling at the destination. Their activity then reproduces and extends the networks, specially to the extent that by migrating they acquire the possibility and the obligation to supply information and help to other potential migrants. Constrained by personal networks, potential migrants fail to consider many theoretically available destinations, and concentrate on those few localities with which their place of origin has strong links (TILLY, 1990, p. 84).

Na verdade, pode-se considerar que, no caso dos movimentos migratórios internos, essa mesma importância deveria ser transferida. Afinal, não há razões para se supor que esses deslocamentos se estruturariam de maneira muito distinta. Talvez algumas das peculiaridades da migração interna estivessem relacionadas ao fato de que, nesse caso, também movimentos de mais curta distância estivessem em jogo. Além disso - e talvez o que é mais importante - as mudanças culturais, sobretudo com relação ao idioma, assim como os riscos da migração, não seriam fatores tão acentuados e possivelmente tão decisivos para a decisão de migrar.
Não obstante seu significado analítico, pelo que se sabe, no Brasil são escassos os estudos, em particular nos anos mais recentes, que recuperam essa dimensão sobre a migração interna. Dessa forma, seria imprescindível que fossem empregados esforços no sentido de incorporar essa problemática, sob pena de se deixar de entender parte significativa do processo migratório - o qual, via de regra, está associado a mudanças estruturais ou, sob outro enfoque, a diferenciais regionais em termos de oferta de empregos, salários, etc.

Para captar adequadamente esse mecanismo, seria necessário promover pesquisas específicas que recuperassem as trajetórias migratórias das famílias ou indivíduos, a partir do levantamento de pontos como "contatos estabelecidos", "informações previamente obtidas", "formas de inserção em termos de moradia", e "existência de parentes ou amigos no destino", etc. - o que nem sempre é simples.

Assim, quase sempre, a utilização de dados censitários acaba sendo a única possibilidade concreta - o que talvez explique a pouca atenção que tem sido dada a essa questão. Talvez, e com razão, a falta de estudos nessa linha seja o reflexo das poucas alternativas visualizadas nos censos para enfrentar esse tema tão intrincado com um mínimo de precisão.

Na verdade, explicitamente, o Censo Demográfico não contempla quesito algum que permita captar diretamente algum aspecto relativo às redes migratórias.

Contudo, mesmo correndo o risco de estar cometendo alguma heresia metodológica, acredita-se que, mesmo de forma muito indireta, a questão das redes poderia ser tratada a partir dos dados censitários. Com alguma criatividade e, principalmente, cautela e critério, sempre se podem extrair do Censo Demográfico pistas sobre vários temas e, nesse caso, não poderia ser diferente.

Nesse sentido, a análise da composição das famílias (ou domicílios ${ }^{23}$ nas áreas de destino dos migrantes, poderia ser pensada como uma forma de detectar indícios sobre a operação das redes no processo migratório. Nesse caso, seria necessário referenciar a análise apenas aos migrantes chefes de famílias já que, dada a estrutura das informações censitárias, somente seria possível recompor a formação do grupo doméstico a partir da relação de parentesco com esse indivíduo.

Seria o caso, pois, de recuperar a composição das famílias em termos de seus componentes, visando obter alguma indicação das redes a partir da existência de outros membros que não estritamente do núcleo familiar, tais como, parentes, agregados, etc. Além disso, seria também possí- 
vel avaliar a composição do domicílio com relação à existência, ou não, de famílias conviventes, fato que, comprovada a condição migratória de uma ou de todas elas, seria uma evidência a mais para amparar a análise.

Contudo, somente isso não seria suficiente. Na verdade, de nada valeria identificar, por exemplo, "famílias estendidas" sem que se tivesse alguma indicação de que as mesmas tenham se formado a partir do estabelecimento das redes requeridas para uma primeira acomodação nas áreas de destino.

Assim, seriam necessários outros procedimentos adicionais para cercar ainda mais a questão. Cotejar a condição migratória (origem e, sobretudo, tempo de residência) do chefe da família com os parentes e agregados, por exemplo, seria uma forma interessante de reconhecer em que medida o grupo doméstico migrou com a formação detectada pelo Censo (ao menos das pessoas nativas da área de destino), ou foi-se formando aos poucos. De certo modo, esse fato configuraria a existência das redes principalmente quando a origem fosse a mesma. É interessante notar que essa metodologia poderia até mesmo ser utilizada para captar tendências à fragmentação e recomposição da família em função da migração (CUNHA, 1994).

Claro está que essas sugestões padecem de várias limitações para abordarem a questão das redes, dentre as quais destaca-se:

- como as informações dizem respeito às famílias referidas no momento do Censo, nada se pode saber das trajetórias das mesmas antes de terem sido recenseadas - o que pode significar, para muitas delas, a não-recuperação da ação das redes no momento de suas chegadas. Assim, os dados obtidos indicariam apenas uma parcela de indivíduos ou famílias que se valeram desse expediente em suas chegadas ao destino;

- nada poderá ser dito com relação à outra "ponta" do processo, ou seja, as áreas de origem, já que todas as relações familiares ou sociais somente poderiam ser captadas no local de destino. Assim, ficaria prejudicada, por exemplo, toda e qualquer análise que pretendesse resgatar os laços (familiares, por exemplo) existentes antes da migração - e que perdurariam mesmo após a mudança como elementos que poderiam motivar fenômenos como a "circularidade" e o retorno futuro;

- finalmente, pela natureza da informação censitária, várias outras questões relativas às redes sequer poderiam ser tangenciadas, tal como seu papel no processo de adaptação e socialização do migrante.

\section{Sobre a Migração Rural-Urbana}

A questão da migração rural-urbana ocupou por muito tempo a agenda migratória nacional, sobretudo nos anos 70. Como lembra Martine (1990), a partir de meados dos anos 60 , iniciou-se uma progressiva e sem precedentes desruralização e concentração urbana derivadas de transformações radicais no campo. A tecnificação, os mecanismos de crédito adotados, a especulação e concentração fundiária restringiram de forma impiedosa o acesso à terra pelos pequenos produtores e reduziram a demanda por mão-deobra, gerando um grande êxodo rural.

Segundo Martine e Camargo (1984), nos anos 60 e 70, o país registrou uma perda de população rural sem precedentes em sua história. Segundo os autores, no primeiro período cerca de 13,5 milhões de pessoas deixaram o campo - volume que aumentou para 15,6 milhões nos anos 70. Além disso, nas décadas de 70/80, o Brasil, pela primeira vez, registrou uma diminuição absoluta de sua população rural.

Na verdade, a migração a partir das áreas rurais em direção às urbanas perdeu significativamente sua intensidade, uma vez que o Censo de 1991 já mostrava que pouco mais de $18 \%$ dos indivíduos que mudaram de município na década de 80 fizeram esse tipo de movimento.

Em contrapartida, os dados mostram que, no mesmo período, parte cada vez mais significativa da migração intermunicipal tinha origem e destino urbano. Assim, a partir desses dados, pode-se dizer que o êxodo rural já teria sofrido importante arrefecimento e, portanto, que a problemática migratória ou, de forma mais geral, da dinâmica socioeconômica e demográfica estariam cada vez mais circunscritas ao contexto das cidades.

Considerando, contudo, a natureza dos dados censitários utilizados para a obtenção dessas estimativas e, principalmente, as novas formas de relações que têm sido observadas entre campo e cidade, algumas questões seriam fundamentais para uma utilização mais apropriada da informação:

- a informação sobre a última residência: uma vez que o Censo pergunta sobre a situação da última residência do indivíduo, é muito provável que, dada a incidência de múltiplos deslocamentos, a migração tipo rural-urbano, por exemplo, seja subestimada. Isso pode ser explicado por uma tendência dos migrantes de buscarem centros urbanos menores antes de se dirigirem para as áreas de destino, onde terão mais tempo de permanência ou fixarão suas residências com um caráter mais definitivo ${ }^{24}$; 
- a informação sobre "data fixa": no caso do Censo de 2000, os movimentos rurais-urbanos são captados a partir da informação sobre a residência cinco anos antes. Nesse caso, portanto, o problema mencionado tenderia a ser atenuado, muito embora tampouco são captados aqueles que mudaram a situação do domicílio há mais de cinco anos;

- o problema da classificação das áreas: se essa questão - que se refere a um procedimento administrativo atribuído ao município - não for devidamente considerada, pode causar transtornos interpretativos. Afinal, a chamada "reclassificação", ou seja, a transformação da condição de áreas rurais em urbanas, via de regra, leva a avaliações incorretas sobre a evolução da população segundo a situação de domicílio. Acredita-se que, muito provavelmente, para algumas regiões do país, parte dos movimentos migratórios do tipo urbano-rural possa ser, por exemplo, simplesmente uma migração para áreas que de fato seriam urbanas e que, no momento do Censo, ainda não tinham sido reclassificadas como tal.

Portanto, é importante levar em conta que os dados censitários sobre situação de domicílio anterior e atual (ou em uma data fixa no passado) parecem ter, hoje em dia, menor significado analítico quando analisados isoladamente. Por isso, para passarem a ganhar nova força interpretativa, tais movimentos deveriam ser avaliados à luz das realidades, em termos da articulação entre os espaços, dos mercados de trabalho, etc.

As reflexões apresentadas a seguir poderão sugerir algumas das dificuldades que podem ocorrer - não apenas para entender os fluxos migratórios entre situação de domicílio, mas também a complexidade para se analisar o processo brasileiro de urbanização.

\section{URBANO E RURAL NO BRASIL: AS DIFICULDADES DE SUA DELIMITAÇÃO}

A análise de uma realidade tão complexa como é a urbanização nos tempos de globalização e reestruturação produtiva (e particularmente em um país com a extensão e diversidade territorial do Brasil) sempre esbarra em dificuldades metodológicas - em especial aquelas relacionadas às características das informações utilizadas.

Além disso, com as novas relações que têm sido observadas mais recentemente entre campo e cidade, acreditase que a questão dos deslocamentos campo-cidade, ou vice-versa, passou a ganhar novos contornos, tanto em termos de seus significados, quanto dos volumes e intensidades envolvidos.

Discutindo as dificuldades teórico-metodológicas para o estudo da urbanização no Brasil no período da industrialização, Faria (1978, p. 100) já considerava que a diversificação e ampliação da divisão social do trabalho que se delineava no país impunham-se

para o conjunto da economia e da sociedade, refazendo ou desfazendo as diferenças genéricas entre o campo e a cidade, unificando os mercados de trabalho urbano e rural.

Da mesma forma, Silva (1997) enfatizava a dificuldade crescente de se delimitar o que é rural e o que é urbano no Brasil, e que "o rural hoje só pode ser entendido como um continuum do urbano, do ponto de vista espacial", posição também defendida por Champion e Hugo (2003). Segundo Silva (1997, p. 43)

do ponto de vista da organização da atividade econômica, as cidades não podem mais ser identificadas apenas com a atividade industrial, nem os campos com a agricultura e a pecuária.

Preocupada com o significado do recorte urbano/rural para o entendimento do processo de urbanização, Patarra (2000, p. 34) alerta para os problemas metodológicos derivados das definições censitárias:

de um lado, são definições montadas a partir da visão dicotômica da realidade social, entre o rural e o urbano [...]; em segundo lugar, por tratar-se de definições ancoradas em critérios administrativos e definidas no nível local de poder, suscitando, muito facilmente, injunções políticas.

A mesma autora, citando o trabalho de Abramovay (1999, p. 39), reconhece que, no Brasil,

a dicotomia rural-urbana [...] é rompida [...] durante os anos 60 , pela noção de continuum rural-urbano, significando a não existência de diferenças fundamentais nos modos de vida, na organização social e na cultura, determinadas por sua vinculação espacial.

Em outra linha de argumento, Veiga (2002) sustenta que o rural brasileiro é muito maior do que o apontado pelos dados do IBGE. De fato, para o autor, esta superestimação do volume de população urbana no Brasil deve-se ao fato de que a definição de urbano vigente no Brasil - que é a mesma desde 1938, com apenas algumas modificações -

transformou em cidades todas as sedes municipais existentes, independentemente de suas características estruturais e funcionais. 
Com isso, ainda segundo o autor, "foram consideradas urbanas todas essas sedes, mesmo que não passassem de ínfimos vilarejos ou povoados" (VEIGA, 2002, p. 3), fato que levaria a um inchamento do setor urbano e, com isso, a profundas distorções da rede urbana brasileira.

Em termos empíricos, umas das primeiras dificuldades advêm das bases conceituais a partir das quais os dados são levantados. De fato, o problema do analista já se apresenta pelo fato de que a definição das categorias "urbano" e "rural" são prerrogativas dos municípios. Por esse motivo, podem não apenas variar de uma região para outra, como também depender de injunções e interesses que, como se sabe, nem sempre obedecem a uma lógica racional ou funcional.

Egler (2001, p. 11) enfatiza

a fragilidade do conceito político-administrativo de população urbana adotado para fins estatísticos no Brasil, que faz com que assentamentos humanos de pouco mais de 100 habitantes sejam considerados como cidades, independente das funções que desempenhem ou dos serviços coletivos que disponham.

Essa opinião é compartilhada por Veiga (2002), que é ainda mais incisivo em sua crítica ao caráter "normativo" da definição do rural e urbano.

Embora sem ainda avançar significativamente no sentido de captar aspectos importantes da divisão social do trabalho, do consumo coletivo, da acessibilidade, ${ }^{25}$ do estilo de vida, etc. (PATARRA, 2000), as novas categorias utilizadas pelo IBGE a partir do Censo de 1991 permitiram, pela primeira vez, uma maior desagregação da informação, possibilitando que a análise dos dados pudesse ir mais além da simplificada dicotomia rural-urbano.

Essas categorias representam basicamente um "gradiente" entre a grande área urbanizada e o rural isolado e, portanto, mesmo ainda limitado - já que mantém a distinção normativa de urbano e rural e as fronteiras "infra-municipais" (VEIGA, 2002) -, permite uma melhor apreensão da heterogeneidade espacial existente, representando, portanto, um grande avanço. ${ }^{26}$

A verdade é que, em um país de tanta diversidade, uma definição mais consistente e possível de ser comparada seria muito importante. Mesmo critérios usados por outros países como, por exemplo, o tamanho de localidade, sua densidade demográfica, etc. (CHAMPION; HUGO, 2003) poderiam ser problemáticos no caso do Brasil, tendo em vista que os significados desses indicadores certamente seriam distintos, dependo do contexto regional em que são mensurados. Vários autores (SAWYER, 1986; EGLER, 2001;
VEIGA, 2002) concordam que, se por um lado o volume e densidade populacional são importantes para a configuração do urbano, também questões funcionais desempenhariam papel fundamental para chegar-se a tal definição.

Por exemplo, tanto Sawyer quanto Veiga defendem o uso de um critério funcional para a definição de "urbano" e "rural". No entanto, esse último ainda advoga a necessidade de se considerar um tamanho mínimo de cidade e densidade. Por sua vez, Sawyer tem uma visão um pouco distinta de Veiga com relação à necessidade de se estabelecer um patamar de tamanho e densidade já que, segundo ele,

ao adotar critérios de tamanho...deve-se levar em conta que nas condições de fronteira, com grande distância, alguns núcleos pequenos em termos populacionais podem exercer funções urbanas importantes ao nível local (SAWYER, 1986, p. 43).

Como se nota, sequer nos critérios demográficos existe um consenso.

É sabido que há grandes diferenças entre as zonas geográficas brasileiras - tanto em termos de seus ecossistemas (que variam da floresta amazônica - no Norte ao pampa gaúcho - no Sul - passando por áreas semi-áridas - no Nordeste - e de cerrado - no Centro-Oeste), quanto em termos de seus processos de ocupação econômica e demográfica, sem contar a dimensão cultural. Assim, é natural que em todo o país, o rural também seja diferenciado regionalmente, como locus de um modo de vida e de produção peculiares.

Assim, pode-se considerar, por um lado, "o moderno rural paulista" e, por outro, o remoto e às vezes inóspito rural do Estado do Mato Grosso, particularmente na sua porção norte.

O primeiro é praticamente "desabitado", particulamente na sua porção norte, ocupada por grandes propriedades de cana-de-açúcar ou de laranja integradas tecnológica e funcionalmente a complexos agroindustriais. É um espaço dotado de total acessibilidade aos centros e mercados urbanos, onde a figura do pequeno agricultor - e, por conseguinte, das pequenas propriedades - foi praticamente substituída pelo típico "trabalhador rural urbanizado": o "bóia-fria". Nesse caso, além da população dita "rural" ter ínfimo peso relativo, parte dela está claramente ligada a atividades urbanas ou tem relações bem definidas com a cidade.

Já em Mato Grosso, cerca de $21 \%$ da população ainda viviam em áreas rurais em 2000. Embora também com a predominância de grandes propriedades dedicadas ao gado 
ou à agricultura temporária (soja, milho e algodão), a densidade demográfica é muito baixa, o grau de acessibilidade é pequeno (quando não quase inexistente), as distâncias e dificuldades de inter-relação com os centros urbanos são muito maiores. Nesse caso, a figura do agricultor familiar ainda aparece como um caso típico do "ser rural". Afinal, o campo é o lugar onde ele vive e de onde retira sua sobrevivência e, quando possível, seus excedentes. Contudo, as relações com o "urbano imediato" existem - sob a forma de trabalhos e permanências temporárias daqueles que necessitam obter algum tipo de ganho financeiro - mesmo que sejam mais difíceis, em função das distâncias a percorrer e, sobretudo da precariedade das estradas. ${ }^{27}$

Outra situação encontra-se nas terras áreas semi-áridas do Nordeste brasileiro, onde as constantes secas, a má qualidade do solo e outros fatores transformaram o espaço rural num verdadeiro "celeiro" de migrantes em potencial que devem a todo instante decidir entre permanecer na miséria total, ou tentar a sorte nas zonas urbanas, em geral localizadas no Sudeste do país ou nas capitais dos próprios Estados. ${ }^{28}$

Assim, acredita-se que tanto o tamanho quanto a densidade têm significados bem distintos, dependendo da região do Brasil da qual se trate. Nesses termos, é um grande desafio para os estudiosos buscar o melhor critério de classificação.

Observando esse tema pelo mundo, em um seminário recentemente realizado, ${ }^{29}$ ficaram claras algumas questões básicas:

- a necessidade de se repensar a "ruralidade" e seu significado no sistema de assentamentos humanos;

- a diversidade de formas de apreensão do que seria "urbano" e "rural";

- como corolário do anterior, a dificuldade de se analisar o processo de "urbanização" de forma comparativa entre os diversos países.

Além dos critérios de "tamanho" e "densidade", que são muito utilizados em países como a Indonésia, por exemplo, há outros bem mais complexos, que envolvem não apenas questões como infra-estrutura e facilidades urbanas, mas também composição da força de trabalho.

Pelo menos no caso do Brasil, acredita-se que as confusões ou imprecisões sobre a configuração do urbano e do rural levam a pelo menos duas problemáticas distintas: A primeira está relacionada à nova realidade das relações entre urbano e rural, como resultado das transformações econômicas, das mudanças na estrutura de preferências pessoais ou familiares, das novas formas de uso e ocupação do solo, etc. Tal realidade tem sido claramente escamoteada pelo uso da ultrapassada dicotomia urbanorural.

Pensada do ponto de vista do processo de metropolitanização, a questão do rural e do urbano reveste-se de um significado ainda mais interessante. Ao reconhecerem que a distinção da população urbana e rural tem-se tornado cada vez mais nebulosa, Champion e Hugo (2003, p.11) alertam para as dificuldades de determinar os limites (boundaries) desses assentamentos, entre outros motivos, porque, segundo eles:

people are moving about more and dividing their lives between areas conventionally designated urban and rural, to a large extent on a daily basis but also in terms of weekly or seasonal movements [...] The result is the emergence of zones of transition around large urban centers where urban and rural functions are mixed together.

De fato, no caso do Brasil, tais “áreas de transição” entre o meio rural e urbano são percebidas com muita clareza no contexto das grandes aglomerações urbanas. Isso ocorre em particular nas áreas metropolitanas, em função do crescimento de áreas cada vez mais distantes do centro principal e pela intensificação dos deslocamentos populacionais no sentido urbano-rural - ou seja, na direção inversa dos que são tradicionalmente estudados no Brasil.

Como se percebe pelos dados obtidos das PNADs dos anos $90,{ }^{30}$ o crescimento demográfico da área rural de várias regiões metropolitanas brasileiras foi bastante significativo, superando, na maioria dos casos, o crescimento do próprio setor urbano - o que contradiz o "padrão urbano" de crescimento das grandes aglomerações.

Assim, é importante notar que, em muitas áreas do país, o crescimento da população rural é, em boa medida, um fenômeno intimamente ligado à expansão urbana. De fato, dados analisados em outro estudo (CUNHA, 2004) mostram que a categoria censitária "aglomerado rural de extensão urbana" apresentou um incremento relativo em praticamente todas as áreas metropolitanas brasileiras entre 1991 e 1996. No entanto, em função da informação censitária disponível, esse processo de expansão urbana acaba sendo escamoteado, como se pôde mostrar em maior detalhe para o Estado de São Paulo (CUNHA; RODRIGUES, 2001).

Ainda nesse caso, percebe-se a importância que os movimentos do tipo "urbano-rural" tenderiam a adquirir, segundo a classificação do Censo Demográfico. Não se pode negar que, embora ainda sejam numericamente pou- 
co expressivos, esses movimentos representam, como processo social, um elemento importante para o entendimento das dinâmicas das metrópoles - já que envolvem pessoas dos variados estratos sociais, cada qual com motivações distintas.

A segunda questão, que não necessariamente contradiz a primeira, refere-se ao sobredimensionamento do urbano brasileiro. Mesmo discordando de certos aspectos (em particular no que se refere à menor importância dada ao critério funcional), não podemos deixar de considerar os argumentos de Veiga (2001) sobre a subestimação do "rural real" - que pode ser constatada ainda hoje - e suas consequiências sobre as políticas de desenvolvimento rural para o país.

Apenas para recordar, listamos alguns de seus argumentos sobre o que Veiga chama de "ficção estatística" sobre o tamanho do urbano. A partir de uma quantificação "alternativa" do rural (baseada em tamanho e densidade, ou seja, observando-se aspectos como rarefação demográfica) o autor afirma que, além de uma normatização caduca que leva em conta o caráter administrativo, é confundido também o setor primário da economia com o "lado rural do território".

Segundo Veiga, pode-se observar claramente que essas duas questões distanciam-se cada vez mais, já que justamente as áreas mais especializadas (como as que produzem commodities) são exatamente as menos dinâmicas - tanto em termos demográficos, como em termos de diversificação e oportunidades para a população. Para ele - e nisso seu argumento concorda com o de Silva (1999) -, o terciário também "invadiu" o mundo rural, e o que se observa cada vez mais é a pluriatividade e o caráter multissetorial da composição de renda dos agricultores. De fato, pode-se constatar que boa parte da população "urbana" no interior do Brasil também está ligada, pelo menos em parte, a atividades rurais.

Mesmo considerando as dificuldades anteriores, é possível pensar em novos dados ou metodologias que melhorassem a apreensão da realidade urbana em um país como o Brasil. Nesse sentido, considera-se fundamental que fontes como os Censos Demográficos avancem na apreensão das novas formas de inserção produtiva ou outras atividades corriqueiras do indivíduo (sociais, educacionais, de consumo, etc.), que reflitam a interação entre os setores urbano e rural, ou entre áreas integradas.

Se, como já se observou, por um lado, os dados levantados pelo IBGE a partir do Censo Demográfico 1991 abriram possibilidades de análise que ultrapassaram a dicotomia pura e simples de "rural" e "urbano", por outro, o engessamento a limites predeterminados pela legislação brasileira ainda os torna muito vulneráveis.

Por onde avançar, então? Pode-se pensar em dados que permitissem um conhecimento a respeito do tipo de atividades desenvolvidas pelos indivíduos, assim como o lo-

TABELA 1

Taxas de Crescimento Médio Anual da População Rural e Urbana, segundo Unidades da Federação Selecionadas Brasil - 1992/99



Fonte: IBGE. Pesquisa Nacional por Amostra de Domicílios - PNAD 1992 e 1999 (tabulação especial - Nepo/Unicamp). 
cal onde acontecem e o tempo dedicado a cada uma delas, por exemplo. Além disso, seria desejável obter informações sobre os locais de consumo e/ou satisfação de necessidades básicas, ${ }^{31}$ assim como dados espacialmente mais desagregados sobre "mudanças residenciais" e "mobilidade pendular". Afinal, esses últimos elementos são fundamentais para uma análise demográfica mais precisa das relações "urbano-rurais", particularmente nas grandes aglomerações urbanas.

Com o desenvolvimento dos Sistemas de Informação Geográfica e da diversificação dos dados espaciais (imagens de satélites, fotos aéreas, mapeamento via GPS, etc.), pode-se pensar em importantes avanços analíticos. Seria possível imaginar uma situação em que os dados coletados em nível domiciliar pudessem ser associados a uma base cartográfica com atributos físicos que completassem a caracterização dos espaços, de modo que fosse obtida uma melhor classificação dos mesmos (como tipo de uso e ocupação do solo, relevo, localização, etc). Combinando informações de distintas naturezas, seria possível chegar a uma melhor configuração dos assentamentos humanos e, quem sabe, ir muito além da velha dicotomia rural/urbano e da visão da expansão urbana a partir do uso das "engessadas" divisões administrativas municipais. ${ }^{32}$

\section{CONCLUSÃO}

O objetivo deste trabalho é apresentar reflexões sobre algumas das questões e dificuldades que advêm do estudo da migração e urbanização no Brasil. Embora com uma preocupação metodológica claramente voltada para a utilização mais intensa e cuidadosa dos dados secundários em particular dos Censos Demográficos - também foram resgatadas várias discussões de cunho teórico que cercam as duas temáticas.

Nesse sentido, no que tange à migração, tentou-se sensibilizar o leitor para as várias possibilidades que se abrem quando se faz um uso criativo e menos convencional dos vários quesitos censitários, sobretudo a partir da combinação deles.

Na verdade, embora com clara preocupação de mostrar as limitações dessas fontes, tratou-se de advogar em favor do uso mais intenso das mesmas e alertar para o seu grande potencial que, muitas vezes não é reconhecido, seja pela pouca familiaridade, seja pela dificuldade de acessos a esses dados.

Procurou-se abordar o que se consideram alguns dos temas mais candentes na atual agenda dos estudos migra- tórios, tentando dar-lhes um tratamento que permitisse não apenas contextualizar as questões, mas também, e principalmente, mostrar como estas poderiam ser exploradas, mesmo que tangencialmente, a partir do uso dos dados censitários.

No caso da urbanização, embora a temática sugira uma enorme amplitude de temas, o foco também foi dado aos elementos mais operacionais relativos à mensuração ou ao dimensionamento da população urbana e rural. No entanto, isso não seria possível sem um esforço de resgatar, ao menos em parte, o debate que se instalou em torno do significado e delimitação do "rural" e do "urbano" brasileiro.

Além de apresentar a preocupação de vários autores sobre o tema e, em particular, a falta de um consenso sobre o assunto, buscou-se mostrar como os dados disponíveis poderiam ser usados para uma melhor compreensão das novas e complexas relações que vêm sendo estabelecidas entre o campo e a cidade.

O leitor, sobretudo o especialista, terá notado que esse trabalho não teve a pretensão de esgotar qualquer tipo de discussão sobre os temas migratórios - muito menos sobre a urbanização - tendo em conta a amplitude das questões que esses fenômenos suscitam. Por exemplo, muito pouco se tratou da relação entre eles - tema que certamente daria material para um outro texto.

De qualquer forma, o que se espera é que este artigo tenha propiciado uma reflexão sobre algumas das dificuldades impostas para o estudo dos fenômenos considerados, além de certos caminhos metodológicos e de análise que poderão contribuir para um melhor conhecimento dessas questões.

No entanto, mais que isso, espera-se que esta contribuição sirva para instigar outros estudiosos na busca de proposições analíticas alternativas, de novas (ou complementares) investigações e, particularmente, para alertar os "produtores de informação" para as necessidades de dados que melhor espelhem as novas realidades da dinâmica sóciodemográfica do país. Não há dúvida de que dois fenômenos tão multifacetados e complexos como a migração e a urbanização demandam (e merecem) maiores investimentos, tanto em pesquisas quanto em novas informações.

Por último, é sempre bom lembrar que os Censos, assim como as PNADs, são fontes cada vez mais acessíveis e talvez as únicas com as quais muitos de nós poderemos contar ao longo de nossas vidas profissionais. Cabe a nós, portanto, "usar e abusar" dessas fontes - mas sempre com muito critério. 


\section{NOTAS}

1. No caso da migração, destacam-se os trabalhos publicados nos Anais do Encontro Nacional sobre Migração, ocorrido em 1997 e 2003. Já para a urbanização, apenas para citar um estudo recente e que já se tornou um clássico, pode-se mencionar a análise da Rede Urbana Brasileira desenvolvida pelo Instituto de Pesquisa Econômica Aplicada - IPEA, Instituto Brasileiro de Geografia e Estatística - IBGE e Núcleo de Economia Social, Urbana e Regional NESUR (1999).

2. De fato, nas projeções mais recentes, o IBGE já incorpora em seus cálculos estimativas da migração internacional. Para maiores detalhes sobre as tendências de migração internacional no Brasil, ver, por exemplo, Patarra e Baeninger (1995).

3. Embora com dados similares e comparáveis aos Censos Demográficos, um dos problemas dessa fonte é que sua representatividade é restrita às Unidades de Federação e Regiões Metropolitanas, o que faz que os dados sobre migração levantados contenham informações apenas sobre os movimentos interestaduais, deixando de contemplar, por exemplo, os deslocamentos intermunicipais que, como se sabe, estão ganhando cada vez mais significado numérico e analítico. De qualquer maneira, embora a grande ênfase do texto seja nos Censos Demográficos, a maior parte dos comentários aqui realizados poderão ser considerados também quando do uso dessa fonte.

4. Este texto, originalmente escrito para refletir sobre os Censos Demográficos, foi adaptado também para o caso da Pesquisa Nacional por Amostras Domiciliares - PNAD e encontra-se em Cunha (2002).

5. As informações são as seguintes: 1. Nacionalidade; 2. Condição de Naturalidade (natural ou não-natural do município de residência); 3. Migração intramunicipal (situação do domicílio anterior rural ou urbano - dentro do município de residência atual); 4. Situação do domicílio (rural ou urbano) no município de residência anterior; 5. Tempo de residência na Unidade de Federação; 6. Tempo de residência no município; 7. Município de residência anterior. Apesar de comparáveis, apenas dois quesitos diferenciam os Censos de 1980 e de 1991: enquanto o primeiro apresenta informação acerca do "município de trabalho ou estudo", no segundo esse quesito foi retirado, mas acrescentou-se informação sobre o "município de residência em 1986". No caso do Censo Demográfico 2000, praticamente as mesmas informações se repetem. Contudo, apesar da manutenção do quesito sobre "UF de residência anterior" o mesmo não ocorreu com o "município de residência anterior", estando presente apenas a informação sobre "município de residência em 1995". Este mesmo ano (1995) também foi utilizado para captar a situação domiciliar prévia à residência onde o indivíduo foi recenseado.

6. Há que se considerar que o município de residência anterior, por exemplo, pode ser, inclusive, um ponto "espúrio" na, às vezes, complexa história dos migrantes.

7. Aqui vale uma referência especial ao mentor da solução, o professor José Alberto Magno de Carvalho do Cedeplar/UFMG.

8. Método proposto por Everet Lee, cujos detalhes podem ser encontrados em Shryock e Siegel (1976).

9. Para que se tenha uma idéia, para o Censo Demográfico 1991, o volume de migrantes intrametropolitanos na Região Metropolitana de Campinas - RMC, com menos de cinco anos de residência captados pela "última residência", é cerca de $26 \%$ maior que a mesma cifra captada pela "data fixa" (65,6 mil contra 51,9 mil). Tal diferença deve-se não apenas à característica de cada uma das informações, mas também em parte porque, no segundo caso, não são computados os menores de 5 anos de idade que, obviamente, não haviam nascido cinco anos antes do levantamento censitário.
10. Ver por exemplo o trabalho de Brito (2004).

11. Como já foi explicitado na nota 9 , o número de migrantes estimado pelos itens "data fixa" e "última residência" para um período de cinco anos serão distintos, mesmo que delimitado por um mesmo lapso de tempo. Isso porque, além de computar crianças menores de 5 anos de idade, a primeira informação captura movimentos de pessoas ocorrido nos cinco anos considerados - o que não é feito pelo item "data fixa".

12. Obviamente esta aproximação seria adequada apenas para os migrantes com tempo de residência menor ou igual a cinco anos, já que apenas para essas durações tem-se a informação desagregada por anos simples. Mesmo assim, no caso do Censo Demográfico 2000, tal operação somente seria possível para a migração interestadual, uma vez que nesse levantamento não mais se coleta a informação sobre "tempo de residência no município".

13. Na verdade, esta é apenas uma das formas possíveis de aproximação do ciclo vital da família, já que outras poderiam ser sugeridas utilizando não apenas a idade dos cônjuges, mas também a idade e número de filhos, etc.

14. Se o cônjuge tiver a mesma origem e tempo de residência do chefe, pode-se supor que aquele tenha migrado com este. Contudo, não se tem a garantia de que isso seja verdadeiro, sem contar que, para chefes viúvos ou separados, é impossível saber o estado civil anterior.

15. A noção de seletividade nos estudos migratórios tem sempre uma conotação comparativa: um grupo é seletivo com relação a outros de referência; portanto, não se trata de um conceito absoluto.

16. O mesmo deve ser dito com relação às comparações entre migrantes com distintos tempos de residência. Em geral, as diferenças encontradas entre os recém-chegados e os mais antigos que, a princípio, podem ser atribuídas ao que se consagrou chamar de processo de adaptação - na verdade parecem refletir outro processo que diz respeito à "sobrevivência" dos migrantes, não apenas com relação à morte, mas sobretudo à reemigracão, que costuma ser importante. Maiores detalhes sobre esse tema podem ser encontrados em Martine (1980).

17. Para uma reflexão mais aprofundada, ver Cunha e Baeninger (2005).

18. Vale a pena mencionar alguns estudos conhecidos sobre o tema, como os de Scott (1995), Rigamonte (1997) e Amaral e Nogueira (1993).

19. Residência-base seria o lugar, ou o conjunto de lugares, a partir do qual os deslocamentos têm uma determinada probabilidade de retorno mais elevado, qualquer que seja a duração da estadia em outro lugar. O migrante em sua residência exterior teria como referência a sua residência-base, matriz de seu universo cultural, incluindo a maneira de organizar sua família, valores morais e religiosos, entre outros.

20. A aplicação desse esquema analítico foi feita em artigo comparando dois grupos distintos de migrantes: os nordestinos e os sulistas. Para maiores detalhes, ver Cunha e Azevedo (2001).

21. Domenach e Piconet (1990) propõem uma tipologia dos deslocamentos, segundo a probabilidade de reversibilidade, com as seguintes categorias: a) uma residência-base sede dos deslocamentos temporários; b) uma residência-base e uma ou mais residências exteriores sucessivas antes do retorno; c) residências-bases sucessivas.

22. Alguns especialistas, entre eles o próprio autor desse texto, têm debatido a idéia de circularidade para conceituar os movimentos de idas e vindas que ocorrem, principalmente, entre o Nordeste e Sudeste.

23. Tendo em vista o reconhecimento da importância das famílias (ou unidades domésticas, para ser mais preciso) no processo mi- 
gratório, acredita-se ser mais recomendável usar essa unidade de análise e não o domicílio que, como se sabe, pode abrigar mais de uma família. Contudo, às vezes, como na Contagem de 1996, por exemplo, essa informação não está disponível, o que leva à necessidade de se considerar o domicílio.

24. Propositalmente, foi-se pouco enfático sobre assumir o caráter definitivo da migração, já que cada vez mais as evidências empíricas, como aumento da migração de retorno, circularidade etc. levam a pensar que essa característica deve ser cada vez mais relativizada.

25. Neste momento de grande mudança e desenvolvimento tecnológico, a questão da acessibilidade deverá ser repensada como critério, já que os significados de tempo, distância, integração, etc. necessariamente estão se redefinindo. Por exemplo: tendências de deslocamentos de pessoas em idade ativa e de certas atividades produtivas para áreas periféricas ou mesmo dos próprios locais de trabalho para o domicílio podem depender mais do acesso "virtual" do que de acessos facilitados, como grandes rodovias ou avenidas.

26. As novas categorias utilizadas pelo IBGE são as seguintes: Área urbanizada, Área não-urbanizada, Área urbana isolada, Aglomerado rural de extensão urbana, Aglomerado rural isolado ou povoado, Aglomerado rural isolado ou núcleo, Outros aglomerados e Área rural (exclusive aglomerado rural).

27. Para uma referência sobre esta questão em Mato Grosso, ver Cunha (2004).

28. Para citar apenas dois estudos mais recentes que tocam de alguma forma essa questão, ver Lyra (2003) e Oliveira (2003).

29. Trata-se do seminário "New Forms of Urbanization: Conceptualizing and Measuring Human Settlement in the Twentyfirst Century", organizado pelo Grupo de Trabalho sobre Urbanização da IUSSP. Bellagio, Itália, 11 a 15 de março de 2002.

30. Vale lembrar que as PNAD's dos anos 90 adotaram a divisão administrativa rural-urbano existente em 1991, sem modificá-la nos vários levantamentos da década. Se por um lado tal procedimento implica em uma distorção da realidade de cada momento, por outro, favorece a análise aqui proposta. Isso porque que os dados diriam respeito sempre à mesma área territorial, evitando interpretações equivocadas sobre a evolução das populações urbana e rural que, como se sabe, podem sofrer modificações através de processos de reclassificação.

31. Nessa linha de análise, vale mencionar o estudo feito pelo IBGE sobre a "Região de Influência das Cidades - REGIC" (IBGE, 1987), que justamente utiliza dados sobre fluxo de pessoas em função da busca de serviço ou consumo para estabelecer critérios de centralidade dos municípios e seus respectivos "hinterlands".

32. Uma aplicação muito interessante dessas possibilidades do geoprocessamento pode ser encontrada em Alves (2004).

\section{REFERÊNCIAS BIBLIOGRÁFICAS}

ABRAMOVAY, R. Do setor ao território: funções e medidas da ruralidade no desenvolvimento contemporâneo. Rio de Janeiro: Ipea, 1999. (Relatório de Pesquisa).

ALVES, H.P.F. Análise dos fatores associados às mudanças na cobertura da terra no Vale do Ribeira através da integração de dados censitários e de sensoriamento remoto. Textos Nepo 47, Campinas, Nepo/Unicamp, 2004.
AMARAL, A.E.P. do.; NOGUEIRA, R.A.M. A volta da Asa Branca: um estudo sobre a migração de retorno a Pernambuco. Recife, Fundação Joaquim Nabuco - Instituto de Pesquisas Sociais, 1993. (Relatório de pesquisa).

BAENINGER, R. Região, Metrópole e Interior: espaços ganhadores e espaços perdedores nas migrações recentes Brasil, 1980-1996. 1999. 234 f. Tese (Doutorado) - Instituto de Filosofia e Ciências Humanas, Universidade Estadual de Campinas, Campinas, 1999.

Redistribución espacial de la población: características y tendencias de caso brasileño. Notas de Población, Santiago de Chile, Año 35, n. 65, 1997.

BOYD, M. Family and personal networks in international migration: recent developments and new agendas. International Migration Review, New York, v. XXIII, n. 3, 1989.

BRITO, F.; GARCIA, R.A.; SOUZA, R.G.V. As tendências recentes das migrações interestaduais e o padrão migratório. In: ENCONTRO NACIONAL DE ESTUDOS DE POPULAÇÃO, 14., 2004, Caxambu. Anais... Campinas: Abep, 2004. (CD-ROM)

CARVALHO, J.A.M. de. Estimativas indiretas e dados sobre migrações: uma avaliação conceitual e metodológica das informações censitárias recentes. Revista Brasileira de Estudos de População, São Paulo, v. 2, n. 1, 1985.

CARVALHO, J.A.M. de; MACHADO, C.C. Quesitos sobre migrações no Censo Demográfico de 1991. Revista Brasileira de Estudos Populacionais, São Paulo, v. 9, n. 1, 1992.

CARVALHO, J.A.M. de; RIGOTTI, J.I. Os dados censitários brasileiros sobre migrações internas: algumas sugestões para análise. In: ENCONTRO NACIONAL DE ESTUDOS POPUlACIONAIS, 11., 1998, Caxambu. Anais... Belo Horizonte: Abep, 1998. (CD-ROM)

CASTIGLIONE, A. Migration, urbanisation et developement. Louvan: CIACO, 1989.

CHAMPION, A. Population distribution in developed countries: has counter-urbanization stopped? In: UNITED NATIONS. Population distribution and migration. New York: United Nations, 1998.

CHAMPION, A.; HUGO, G. New forms of urbanization: beyond the urban-rural dichotomy. Burlington/USA: Ashgate, 2003.

CUNHA, J.M.P. Dinâmica migratória e o processo de ocupação do Centro-Oeste Brasileiro: o caso de Mato Grosso. Campinas, 2004. (Relatório de Pesquisa). Mimeografado.

O uso das PNADs na análise do fenômeno migratório: possibilidades, lacunas e desafios metodológicos. Rio de Janeiro: Ipea, 2002. (Texto para Discussão, n. 875).

Mobilidade populacional e expansão urbana: o caso da Região Metropolitana de São Paulo. 1994. 283 f. Tese (Doutorado) - Instituto de Filosofia e Ciências Humanas, Universidade Estadual de Campinas, Campinas, 1994.

Impactos da migração intercensitária em algumas características demográficas do Estado de São Paulo (1970/80). In: ENCONTRO NACIONAL DE ESTUDOS POPULACIONAIS, 6., 1988, Olinda. Anais... Brasília: Abep, 1988

CUNHA, J.M.P.; AZEVEDO, M.M. Demographic and sociocultural aspects of population mobility in Brazil. In: HOGAN, D.J. (Org.). Population change in Brazil: contemporary perspectives. Campinas: Nepo/Unicamp, 2001. 
CUNHA, J.M.P.; BAENINGER, R. Cenários da migração no Brasil nos anos 90. Caderno do CRH, Salvador, v. 18 n. 43, 2005. No prelo.

CUNHA, J.M.P.; OLIVEIRA, A.A.B. de. População e espaço intra-urbano em Campinas. In: HOGAN, D.J. et al. (Org.). Migração e ambiente nas aglomerações urbanas. Campinas: Nepo/Unicamp-Pronex, 2001.

CUNHA, J.M.P.; RODRIGUES, I.A. Transition space: new standpoint on São Paulo state's (Brazil) population redistribution process. In: IUSSP GENERAL POPULATION CONFERENCE, 24., 2001, Salvador. Anais... Liege: IUSSP, 2001.

DOMENACH, H.; PICONET, M. El caráter de la reversibilidad en el estudio de la migración. Notas de Población, Santiago de Chile, Celade, n. 49, 1990.

EGLER, C. Mudanças recentes no uso e na cobertura da terra no Brasil. Campinas, 2001. (Texto apresentado no seminário mudanças ambientais globais: perspectivas). Mimeografado.

FARIA, V. A conjuntura social brasileira: dilemas e perspectivas. Novos Estudos Cebrap, São Paulo, n. 33, 1992.

O processo de urbanização no Brasil: algumas notas para seu estudo e interpretação. In: ENCONTRO NACIONAL DE ESTUDOS POPULACIONAIS, 1., 1978, Campos do Jordão. Anais... São Paulo: Abep, 1978.

GOLDANI, A.M. Componentes demográficos do crescimento urbano: Região Metropolitana de São Paulo. In: ENCONTRO NACIONAL DE ESTUDOS POPULACIONAIS, 2., 1980, São Paulo. Anais... São Paulo: Abep, v. 1, 1980.

IBGE. Regiões de influência das cidades. Rio de Janeiro: 1987. (Revisão atualizada do estudo "Divisão do Brasil em Regiões Funcionais e Urbanas").

IPEA/IBGE/NESUR. Caracterização e tendências da rede urbana do Brasil. Campinas: IE/Unicamp, 1999.

LAGO, L.C. Divisão sócio-espacial e mobilidade residencial: reprodução ou alteração das fronteiras espaciais? In: ENCONTRO NACIONAL DE ESTUDOS POPULACIONAIS, 12., 2000, Caxambu. Anais... Campinas: Abep, 2000.

Estruturação urbana e mobilidade espacial: uma análise das desigualdades socioespaciais na Metrópole do Rio de Janeiro. 1998. 254 f. Tese (Doutorado) - Faculdade de Arquitetura e Urbanismo, Universidade de São Paulo, São Paulo, 1998.

LYRA, M.R.B. O processo de migração de retorno no fluxo Pernambuco - São Paulo - Pernambuco. 2003. 258 f. Tese (Doutorado em Demografia) - Instituto de Filosofia e Ciências Humanas, Universidade Estadual de Campinas, Campinas, 2003.

MARTINE, G. As migrações de origem rural no Brasil: uma perspectiva histórica. In: FUNDAÇÃO SEADE. História e população: estudos sobre a América Latina. São Paulo: Fundação Seade, 1990.

Os dados censitários sobre migrações internas: evolução e utilizações. In: ENCONTRO NACIONAL DE ESTUDOS POPULACIONAIS, 4., 1984, Águas de São Pedro. Anais... São Paulo: Abep, v. 1, 1984.

Adaptação dos migrantes ou sobrevivência dos mais fortes? In: MOURA, H. (Org.). Migração interna: textos selecionados. Fortaleza: Banco do Nordeste do Brasil S.A., 1980.

et al. A urbanização no Brasil: retrospectiva,

componentes e perspectivas. In: ENCONTRO NACIONAL DE
ESTUDOS POPULACIONAIS, 6., 1988, Olinda. Anais... Brasília: Abep, 1988.

MARTINE, G.; CAMARGO, L. Crescimento e distribuição da população brasileira: tendências recentes. Revista Brasileira de Estudos de População, São Paulo, v. 1, n. 1, 1984.

MASSEY, D. et al. Return to aztlan. Berkeley: University of California Press, 1987

MATOS, R.E.S. A desconcentração populacional em Minas Gerais e as mudanças na Região-Core. In: ENCONTRO NACIONAL DE ESTUDOS POPULACIONAIS, 9., 1994, Caxambu. Anais... Belo Horizonte: Abep, 1994.

MOURA, H.A. A identificação do migrante de retorno através da informação censitária. [s/d] Mimeografado.

NACIONES UNIDAS. Métodos de medición da la migración interna. Nueva York: Naciones Unidas, 1972. (Manual VI).

OLIVEIRA, K.F. Dinâmica migratória em Sergipe dos anos 70 aos 90: uma análise a partir de alguns fatores estruturais. 2003. 151 f. Dissertação (Mestrado em Pesquisas Sociais e Estudos Populacionais) - Escola Nacional de Ciências Estatísticas ENCE/IBGE, Rio de Janeiro, 2003.

PACHECO, C.A. Fragmentação da nação. Campinas: IE/ Unicamp, 1998.

PATARRA, N. Do urbano às novas territorialidades: conceitos e questões. Rio de Janeiro: Ipea, 2000. (Relatório de Pesquisa).

PATARRA, N.; BAENINGER, R. Migrações internacionais recentes: o caso do Brasil. In: PATARRA, N. (Coord.). Emigração e imigração internacionais no Brasil Contemporâneo. Campinas: Nepo/Unicamp; Nesur; Unfpa, 1995.

RIBEIRO, J.T.L. Estimativa da migração de retorno e de alguns de seus efeitos demográficos indiretos no Nordeste Brasileiro. 1997. Tese (Doutorado) - Cedeplar, Universidade Federal de Minas Gerais, Belo Horizonte, 1997

Efeitos demográficos da migração de retorno: uma proposta metodológica. In: ENCONTRO NACIONAL DE ESTUDOS POPULACIONAIS, 10., 1996, Caxambu. Anais... Belo Horizonte: Abep, v. 2, 1996.

RIBEIRO, J.T.L.; CARVALHO, J.A.M.; WONG, L.R. Migração de retorno: algumas possibilidades de mensuração. In: ENCONTRO NACIONAL DE ESTUDOS POPULACIONAIS, 10., 1996, Caxambu. Anais... Belo Horizonte: Abep, v. 2, 1996.

RIGAMONTE, R.C. Sertanejos contemporâneos: entre a metrópole e o sertão. 1997. 171 f. Dissertação (Mestrado) Faculdade de Filosofia, Letras e Ciências Humanas, Universidade de São Paulo, São Paulo, 1997.

RIGOTTI, J.I.R. Técnicas de mensuração das migrações, a partir de dados censitários: aplicação aos casos de Minas Gerais e São Paulo. 1999. Tese (Doutorado) - Cedeplar, Universidade Federal de Minas Gerais, Belo Horizonte, 1999.

RIGOTTI, J.I.R.; RODRIGUES, R.N. Distribuição espacial da população na Região Metropolitana de Belo Horizonte. In: ENCONTRO NACIONAL DE ESTUDOS POPULACIONAIS, 9., 1994, Caxambu. Anais... Belo Horizonte: Abep, 1994

SALIM, C.A. Estrutura agrária e dinâmica migratória na Região Centro-Oeste, 1970-1980: análise do êxodo rural e da mobilidade da força de trabalho no contexto de industrialização da agricultura e da fronteira urbanizada. 1992. Tese (Doutorado 
em Demografia) - Cedeplar/FCACE, Universidade Federal de Minas Gerais, Belo Horizonte, 1992.

SAWYER, D. Urbanização da fronteira agrícola no Brasil. In: LAVINAS, L. (Org.). A urbanização da fronteira. Rio de Janeiro: IPPUR/UFRJ, 1986.

SCOTT, R.P. Estratégias familiares de emigração e retorno no Nordeste. Revista Travessia, São Paulo, Ano VIII, n. 22, 1995.

SHRYOCK, H.S.; SIEGEL, J. The methods and materials of demography. New York: Academic Press, 1976.

SILVA, J.G. da. O novo rural brasileiro. Campinas: IE/Unicamp, 1999.

O novo rural brasileiro. Nova Economia, Belo Horizonte, v. 7, n. 1, 1997

et al. O rural paulista: muito além do agrícola e do agrário. São Paulo em Perspectiva, São Paulo, Fundação Seade, v. 10, n. 2,1996

SPOSATI, A. Cidade em pedaços. São Paulo: Brasiliense, 2001.

(Coord.). Mapa da exclusão/inclusão social da cidade de São Paulo/2000: dinâmica social dos anos 90. São Paulo: PUC-SP/POLIS/INPE, 2000. (CD-ROM).

TILLY, C. Transplanted networks. In: YANS-MACLAUGHLIN, V. (Ed.). Immigration reconsidered: history, sociology and politics. Oxford: Oxford University Press, 1990.
TORRES, H. da G. Desigualdade ambiental na cidade de São Paulo. 1997. 256 f. Tese (Doutorado) - Instituto de Filosofia e Ciências Humanas, Universidade Estadual de Campinas, Campinas, 1997.

TORRES, H. da G.; COSTA, H. (Org.). População e meio ambiente: debates e desafios. São Paulo: Senac, 2000.

VEIGA, J.E. Cidades imaginárias: o Brasil é menos urbano do que se calcula. Campinas: Editora Autores Associados, 2002.

Desenvolvimento territorial do Brasil: do entulho Varguista ao Z.E.E. Disponível em: <http://www.fea.usp/ professores/zeeli/ultimos>. Acesso em: 2002.

et al. O Brasil rural precisa de uma estratégia de desenvolvimento. Brasília: Convênio Fipe-IICA (MDA/CNDRS/ NEAD), 2001

José Marcos Pinto da Cunha: Demógrafo, Professor do Instituto de Filosofia e Ciências Humanas e do Núcleo de Estudos de População, ambos da Unicamp.

Artigo recebido em 17 de março de 2005.

Aprovado em 6 de abril de 2005. 